\title{
Host Decoy Trap (HDT) with cattle odour is highly effective for collection of exophagic malaria vectors
}

Bernard Abong' ${ }^{1,2,3^{*}} \mathbb{D}$, Xiaoyu Yư ${ }^{4}$, Martin J. Donnelly ${ }^{1}$, Martin Geier ${ }^{5}$, Gabriella Gibson ${ }^{6}$, John Gimnig ${ }^{7}$, Feiko ter Kuile ${ }^{1}$, Neil F. Lobo ${ }^{4}$, Eric Ochomo ${ }^{2}$, Stephen Munga ${ }^{2}$, Maurice Ombok ${ }^{2}$, Aaron Samuels ${ }^{8}$, Stephen J. Torr ${ }^{1}$ and Frances M. Hawkes ${ }^{6}$

\begin{abstract}
Background: As currently implemented, malaria vector surveillance in sub-Saharan Africa targets endophagic and endophilic mosquitoes, leaving exophagic (outdoor blood-feeding) mosquitoes underrepresented. We evaluated the recently developed host decoy trap (HDT) and compared it to the gold standard, human landing catch (HLC), in a $3 \times 3$ Latin square study design outdoors in western Kenya. HLCs are considered to represent the natural range of Anopheles biting-behaviour compared to other sampling tools, and therefore, in principle, provide the most reliable profile of the biting population transmitting malaria. The HDT incorporates the main host stimuli that attract blood-meal seeking mosquitoes and can be baited with the odours of live hosts.

Results: Numbers and species diversity of trapped mosquitoes varied significantly between HLCs and HDTs baited with human (HDT-H) or cattle (HDT-C) odour, revealing important differences in behaviour of Anopheles species. In the main study in Kisian, the HDT-C collected a nightly mean of 43.2 (95\% Cl: 26.7-69.8) Anopheles, compared to 5.8 (95\% Cl: 4.1-8.2) in HLC, while HDT-H collected 0.97 (95\% Cl: 0.4-2.1), significantly fewer than the HLC. Significantly higher proportions of An. arabiensis were caught in HDT-Cs $(0.94 \pm 0.01$; SE) and HDT-Hs $(0.76 \pm 0.09$; SE) than in HLCs $(0.45 \pm$ 0.05; SE) per trapping night. The proportion of An. gambiae (s.s.) was highest in HLC ( $0.55 \pm 0.05$; SE) followed by HDT-H $(0.20 \pm 0.09 ; \mathrm{SE})$ and least in HDT-C (0.06 $\pm 0.01 ; \mathrm{SE})$. An unbaited HDT placed beside locales where cattle are usually corralled overnight caught mostly An. arabiensis with proportions of $0.97 \pm 0.02$ and $0.80 \pm 0.2$ relative to the total anopheline catch in the presence and absence of cattle, respectively. A mean of 10.4 (95\% Cl: 2.0-55.0) Anopheles/night were trapped near cattle, compared to 0.4 (95\% Cl: 0.1-1.7) in unbaited HDT away from hosts.

Conclusions: The capability of HDTs to combine host odours, heat and visual stimuli to simulate a host provides the basis of a system to sample human- and cattle-biting mosquitoes. HDT-C is particularly effective for collecting An. arabiensis outdoors. The HDT offers the prospect of a system to monitor and potentially control An. arabiensis and other outdoor-biting mosquitoes more effectively.
\end{abstract}

Keywords: Anopheles, An. arabiensis, An. gambiae (s.s.), Vector behaviour, Host, Odour, Mosquito trap, Exophily

\footnotetext{
*Correspondence: Bernard.Abongo@|stmed.ac.uk; abongoben@gmail.com 'Liverpool School of Tropical Medicine, Pembroke Place, Liverpool L3 5QA, UK

${ }^{2}$ Centre for Global Health Research, Kenya Medical Research Institute, PO Box 1578-40100, Kisumu, Kenya

Full list of author information is available at the end of the article
}

(c) The Author(s). 2018 Open Access This article is distributed under the terms of the Creative Commons Attribution 4.0 International License (http://creativecommons.org/licenses/by/4.0/), which permits unrestricted use, distribution, and reproduction in any medium, provided you give appropriate credit to the original author(s) and the source, provide a link to the Creative Commons license, and indicate if changes were made. The Creative Commons Public Domain Dedication waiver (http://creativecommons.org/publicdomain/zero/1.0/) applies to the data made available in this article, unless otherwise stated. 


\section{Background}

Sustained use of long-lasting insecticide treated nets (LLINs) and indoor residual spraying (IRS) have reduced malaria infection prevalence by half between 2000 and 2015, with LLINs and IRS contributing an estimated 68 and $11 \%$ of this decline, respectively [1]. Significant changes in vector populations have also been observed with sustained implementation of LLINs [2-4]. Both interventions, however, are limited to indoor application and are therefore more effective against indoor resting ('endophilic') and indoor feeding ('endophagic') mosquitoes and less so against those that feed and rest outdoors, such as An. arabiensis and An. culicifacies [5]. Sustained use of LLINs and IRS may also select for outdoor resting ('exophily') and feeding ('exophagy') in mosquito populations [6-8], day-time feeding [9] and a shift towards non-human hosts ('zoophagy'), such as cattle [10]. Mosquito populations that feed or rest outdoors may play an important role in the maintenance of malaria transmission after implementation of LLINs or IRS [7]. Accordingly, there is a pressing need for better methods to control and monitor these species.

Methods for sampling adult mosquitoes often exploit host-oriented behaviour. For instance, use of the human landing catch (HLC) or placement of CDC-light traps adjacent to a human under a bednet [11] rely on the attraction of mosquitoes to their host [12-14]. Hitherto, research to develop devices to attract malaria mosquitoes has focused largely on human odours. Identification of the chemicals present in human odour has led to the development of blends of artificial odours [15], which have been used with Mosquito Magnet $^{\oplus}$ X (MMX) [16] and Suna [17] traps to sample and control [18] An. gambiae (s.l.). However, the design of some of these traps, such as light traps, are dependent on actively aspirating mosquitoes via a fan, thereby limiting catch efficacy, as odours induce only part of the behavioral sequence that leads a mosquito to a host [19]. Artificial odour blends in isolation do not fully mimic the range of physical and visual stimuli that attract mosquitoes to natural hosts, particularly those that most influence their close-range orientation behaviour [20-22].

Laboratory studies have begun to quantify synergistic effects between olfactory, visual and thermal cues on mosquito behaviour during host location [21, 23]. These developments can contribute to more effective ways to measure vector-host contact, particularly in outdoor environments, where HLCs remain an important means of sampling, despite exposing collectors to mosquito bites and data quality relying on individual collector skill [22]. A recent study showed that exploitation of the responses of mosquitoes to the heat produced by hosts may be a potent tool for monitoring and controlling outdoor-biting species of mosquito; the host decoy trap (HDT), which combines natural human odour, visual stimuli, and a thermal signature equivalent to the human body, caught between two and tenfold more An. coluzzii than a field technician performing HLC outdoors [24], even though $A n$. coluzzii is generally considered a primarily endophagic and endophilic species.

In East and Southern Africa, An. gambiae (s.s.), An. arabiensis and An. funestus are important vectors of malaria. Anopheles arabiensis feeds mostly outdoors on humans and cattle [25-27] while An. gambiae (s.s.) and An. funestus mostly feed indoors on humans [2, 26, 27]. In western Kenya, we tested the relative performance of HDTs baited with either natural human (HDT-H) or cattle (HDT-C) odours against HLC to attract and trap outdoor biting mosquitoes and assessed whether natural host odours might provide an effective basis for systems to monitor and control exophagic and zoophagic vectors of malaria.

\section{Methods \\ Study area}

The study was conducted in Kisian village $\left(0.0749^{\circ} \mathrm{S}\right.$, $\left.34.6663^{\circ} \mathrm{E}\right)$, near the Kenya Medical Research Institute Centre for Global Health Research (KEMRI-CGHR) in Kisumu County, and in Orego village $\left(0.6167^{\circ} \mathrm{S}, 34.55^{\circ}\right.$ E), Homa Bay County, western Kenya, in May and June 2017. Western Kenya is malaria endemic with transmission occurring throughout the year. The region has two wet seasons, March to June and October-December, corresponding to periods of highest malaria transmission. Residents are predominantly of Luo ethnic group practicing small-scale mixed crop farming and raising livestock including cattle and goats. Anopheles funestus, An. arabiensis and An. gambiae (s.s.) are the main malaria vectors in the study area. The region has high coverage with LLINs ( $>85 \%$ of households with at least one net) [28].

\section{Mosquito collection methods Host decoy trap (HDT)}

A standardized HDT was manufactured by the University of Greenwich and Biogents AG (BG-HDT version) using the same principles as the prototype described in Hawkes et al. [24]. It consists of a watertight lay-flat plasticized aluminium foil container similar to packets of single-use fruit juice drinks, insulated with layers of polystyrene held in a collapsible cylindrical bucket (height $36 \mathrm{~cm}$, diameter $38 \mathrm{~cm}$ ), around which a black fabric jacket is secured using hook and eye strips. The watertight bag is filled with $\sim 15 \mathrm{l}$ of water heated to $\sim 80{ }^{\circ} \mathrm{C}$, which is sufficient to maintain surface temperature across the fabric jacket of $30-40{ }^{\circ} \mathrm{C}$ for at least 12 hours. The bucket is closed with a transparent polyethylene plastic cover to protect the interior from rain. This unit provides 
high contrast visual stimuli and human-equivalent thermal stimuli to induce close-range attraction and landing behaviour in host-seeking mosquitoes. A transparent adhesive plastic sheet (FICS film, Barrettine Environmental Health, Bristol, UK) covers the circumference of the trap (Fig. 1a) to catch mosquitoes as they land. In contrast, the original host decoy trap (O-HDT) consisted of metal cooking pot or plastic barrel/container ( 40 l), with 15-20 1 of hot water. The container was insulated with towelling material to maintain the surface temperature at $30-40{ }^{\circ} \mathrm{C}$. A black fabric "jacket" was sewn to fit over the insulating material to provide a strong visual contrast against the background.

To provide natural host odours, two tents made from canvas supported by a metal frame, each measuring 2.0 $\mathrm{m}$ high $\times 2.0 \mathrm{~m}$ square were used to house odour baits (Fig. 1a). One tent was assigned to a cow and another to a human volunteer throughout the study period. Tents were aerated and rotated between the trapping sites each night. A $12 \mathrm{~V}$ fan (Biogents AG) connected to a $10 \mathrm{~m}$ length of PVC tubing (10 $\mathrm{cm}$ in diameter) was placed inside the tent (Fig. 1b). The other opening of the tube was covered with untreated mosquito netting and placed $\sim 10 \mathrm{~cm}$ from the base of the HDT unit, thus venting host odours from the tent around the trap at approximately $2000 \mathrm{l} / \mathrm{min}$ (Fig. 1c). Carbon dioxide produced by both cow and human baited tents was measured at the pipe outlet using a $\mathrm{CO}_{2}$ meter (EGM-4, PP Systems, Amesbury, MA, USA). The values were adjusted to consider background levels of $\mathrm{CO}_{2}$ (400 ppm). The cow-odour released $\sim 0.6 \mathrm{l} / \mathrm{min} \mathrm{CO}_{2}$ from the pipe outlet, about three times more than the human-odour released $(\sim 0.2 \mathrm{l} / \mathrm{min})$, consistent with an approximately three-fold difference in their weights.
In principle, mosquitoes following odour plumes emanating from the end of the PVC tube see the HDT and approach it. They then encounter the warmth of the trap's surface, whereupon they land and become stuck to the transparent adhesive sheet (Fig. 2a). At the end of the sampling period a thinner plastic sheet of transparent polyethylene wrap (cling film/food wrap) was laid on the surface of the adhesive sheet, sandwiching trapped mosquitoes between the two sheets (Fig. 2b). Using a razorblade, the sheets were cut and removed from the HDT and mosquitoes were later removed from the sheets in the laboratory using Romax Glue Solvent (Barrettine Environmental Health, Bristol, UK).

Whole host odours were used to attract mosquitoes to HDTs. Four cows, each weighing 150-200 kg were used individually to provide natural odours in the experiment. Each cow was used for six consecutive nights before being replaced (Fig. 1a). Eight field assistants working in pairs conducted the experiments, with each pair participating for six consecutive nights before being replaced. The field assistants worked in two shifts (18:00 to $12: 00 \mathrm{~h}$ and 12:00 to 07:00 $\mathrm{h}$ ), changing places each night to perform either an outdoor HLC or sleeping in the tent to provide human odour for the HDT-H.

\section{Human landing catch (HLC)}

Field assistants performing HLCs sat outside at the same locations as the HDT sites, with their trousers folded to knee height and caught mosquitoes landing on their exposed lower limbs using a mouth aspirator. Collections were performed for $45 \mathrm{~min}$ and the collectors rested 15 min in each collection hour. Collected mosquitoes were placed in paper cups and were sustained on $10 \%$ sugar solution before transportation to the laboratory for analysis.
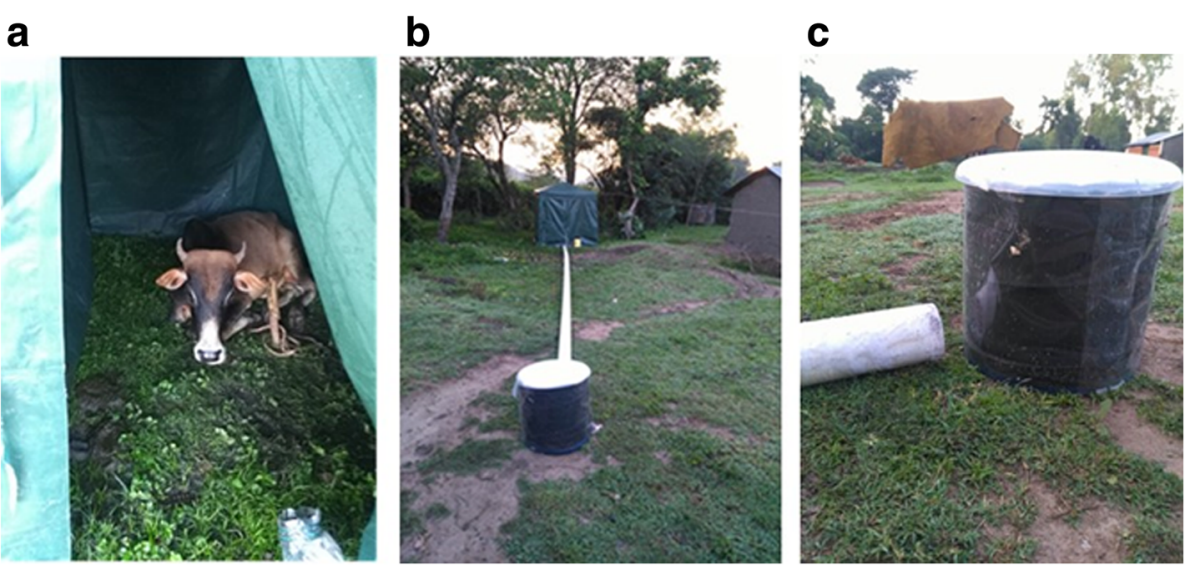

Fig. 1 Host Decoy Trap (BG-HDT) set-up. a Cow tethered inside tent provides natural host odour and carbon dioxide for baiting HDT. b Experimental set-up showing host-occupied tent, PVC pipe (fan inside pipe directs host odour to trap) and HDT. c Pipe opening releases host odour within $10 \mathrm{~cm}$ of the HDT. Visual stimuli of the dark trap and warmth of water-filled trap induce mosquitoes to land on clear adhesive sheet covering dark surface of the trap 

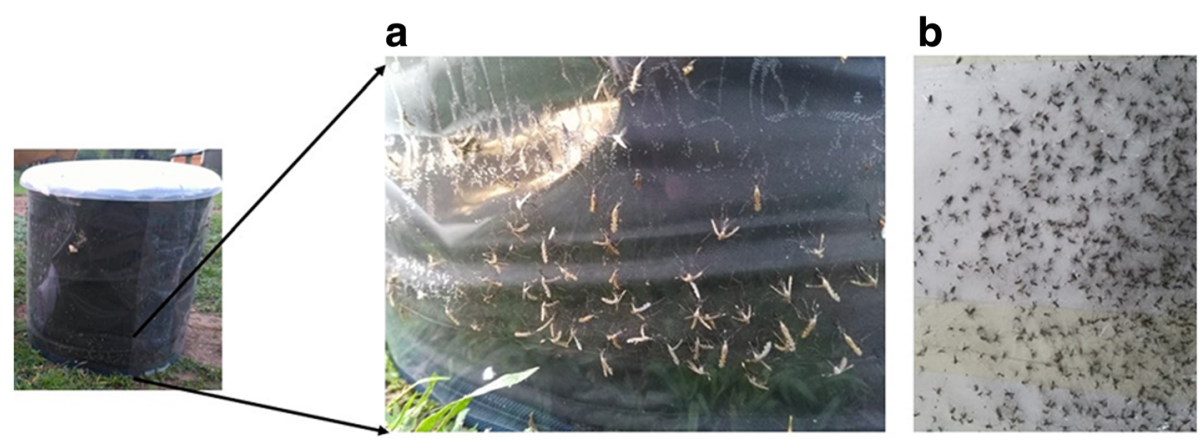

Fig. 2 Mosquitoes collected by Host Decoy Traps (HDT). a A section of the HDT showing trapped mosquitoes stuck to clear adhesive sheet. b Trapped mosquitoes recovered from HDT by removing adhesive sheet from the trap and covering it with a layer of thin plastic food wrap before species identification in the laboratory

\section{Species identification and parasite detection}

Mosquitoes were sorted to subfamilies to separate anopheline from culicine species. In each subfamily, mosquitoes were further separated by abdominal status as either fed, unfed, gravid or half gravid. All Anopheles mosquitoes were identified morphologically to species $[29,30]$ and then placed singly in $1.5 \mathrm{ml}$ micro-centrifuge tubes for further laboratory analysis. Species were identified by PCR for An. gambiae (s.l.) [31] and An. funestus (s.l.) group [32] and sporozoite rate was determined by enzyme linked immunosorbent assay (ELISA) [33].

\section{Experiment 1: Comparison of catches from HDTs and HLCs}

We investigated the host choices of outdoor-biting malaria vectors using the BG-HDT, baited with either human or cattle odour, and compared these catches with the HLC. Our null hypothesis was that an HLC and the HDTs baited with cow (HDT-C) or human (HDT-H) odour would catch equal numbers of mosquitoes with the same species composition in an outdoor peri-domestic environment. A replicated Latin Square experimental design of collection methods $\times$ sites $\times$ nights was conducted. Collection sites were $100 \mathrm{~m}$ from each other. The experiment was carried out twice, first (May 2017) in Kisian village, Kisumu county, and subsequently (June 2017) in Orego village, Homa Bay county. Collections ran from 18:00 $\mathrm{h}$ to $07: 00 \mathrm{~h}$ for 24 nights in Kisian village and 12 nights in Orego village.

\section{Experiment 2: Catches from un-baited HDT}

In the second experiment, we tested whether mosquitoes would be attracted to an unbaited BG-HDT (i.e. operated without any host odours released from the tent) placed within $5 \mathrm{~m}$ of a corralled herd of cattle. The main aim was to determine whether dispersed host odour is sufficient to attract mosquitoes close enough to the HDT to induce them to land on the warm, visually conspicuous trap. Two pairs of neighbouring compounds in Kisian village were chosen for this study, each $\sim 100 \mathrm{~m}$ apart. Within each pair, approximately 10 cattle were present in one compound and absent in the other. The BG-HDT (excluding tent and pipe used to deliver odours in Experiment 1) was placed next to the corralled cattle herd or in the centre of the compound where cattle were absent. Trapping was performed for six consecutive nights in each pair of compounds between 18:00 $\mathrm{h}$ and 07:00 $\mathrm{h}$.

\section{Experiment 3: Trap validation - does the BG-HDT catch similar abundance and species composition as the original HDT?}

In Experiment 3, we tested whether the commercially produced BG-HDT performed as well as the original proof of concept trap used in Hawkes et al. [24], with an additional reference HLC, with respect to mosquito species composition and abundance. We constructed an HDT in accordance with the protocol available at https://doi.org/10.17504/protocols.io.n95dh86. A $3 \times 3$ Latin Square was conducted in Kisian, comparing HLC, BG-HDT and the original version (O-HDT), both baited with human odour as described in Experiment 1, with the exception that small one-person tents were used. This experiment was completed over 24 nights from May to June 2017.

\section{Data analysis}

Analysis was done using $\mathrm{R}$ statistical software version 3.4.1. Data were fitted using Generalized Linear Mixed Effects Statistical Models (GLMMs) to describe effects of collection method on mosquito catches. Since the data were over-dispersed, we used the package $\operatorname{glmm} A D M B$ [34] to fit negative binomial distribution models for the analysis of mosquito numbers. The numbers of female Anopheles mosquitoes were assessed as a function of collection method as a fixed effect, and collection sites and days were treated as random effects. A binomial GLM model was used to analyse Anopheles species densities per trapping method and a pairwise comparison of means of Anopheles species between different trapping methods done by Tukey's post-hoc test. 


\section{Results}

Altogether 1807 Anopheles and 22,333 culicine mosquitoes were collected in Experiments 1, 2 and 3 combined. Samples collected by HDT were mostly unfed, while HLC yielded the highest proportion of fed Anopheles ( $n=21 ; 17.10 \%)$, whereas there were only 6 blood-fed in HDT-C and none in HDT-H (Table 1). All mosquitoes collected by HDT were in good enough condition for morphological identification, PCR and sporozoite ELISA procedures.

\section{Experiment 1: Comparison of catches from HDTs and HLCs} Generalized Linear Mixed Effects Statistical Models (GLMMs) was used to all statistical tests. The estimated mosquito abundance in Kisian village differed significantly by trap type. The HDT-C collected a nightly average of 43.2 (95\% CI: 26.7-69.8) Anopheles, compared to 5.8 (95\% CI: 4.1-8.2) in HLC $(z=-8.99, P<0.001)$, while HDT-H collected 0.97 (95\% CI: 0.4-2.1) per night, significantly fewer Anopheles than the HLC $(z=-6.00, P$ $<0.001)$. A similar pattern was observed in mean nightly catch of culicine species. These were significantly higher in HDT-C with a mean of 349.6 (95\% CI: 208.5-586.3) compared to 70.5 in HLC (95\% CI: 46.5-106.7), $(z=$ $-10.10, P<0.001$ ), while the HDT-H collected 22.9, the fewest culicine mosquitoes (95\% CI: 13.6-38.8), significantly less than the HLC $(z=-7.05, P<0.001$; Fig. 3a).

Overall abundance of Anopheles in Homa Bay showed a trend of significantly higher numbers of mosquitoes in HDT-C, compared to the other methods. In Homa Bay, a mean of 7.5 (95\% CI: 2.8-19.9) Anopheles were collected by HDT-C each night, compared to 1.0 (95\% CI: $0.4-2.3)$ in HLC, $(z=5.31, P<0.001)$. No significant difference was found between catches in HLC and HDT-H with a mean of 0.5 (95\% CI: $0.1-2.1 ; z=-1.26, P=0.21$ ). As in Kisian, a significantly higher mean number of culicine mosquitoes, 18.9 (95\% CI: 7.5-47.3), were also collected by HDT-C each night in Homa Bay, compared to 1.3 (95\% CI: 0.7-2.6) in HLC ( $z=6.61, P<0.001$; Fig. 3b).

Both cattle- and human-baited HDTs almost exclusively collected unfed female Anopheles (97.4\%) while fed Anopheles accounted for $17 \%$ of HLC samples (Table 1). Sporozoite infection rates were $1.4 \%(9 / 635)$ in HDT-C, $5.5 \%(1 / 18)$ in HDT-H and $0.9 \%(1 / 111)$ in HLC. Sporozoite infection was $0.97 \%(9 / 921)$ in An. arabiensis and $1.64 \%$ (2/122) in An. gambiae (s.s.).

Proportions of Anopheles species with respect to total anopheline numbers, varied according to trapping method and field location (Fig. 4). From HDT-C collections, An. arabiensis comprised the highest proportion of all Anopheles species caught in both Kisian (0.94 \pm $0.01)$ and Homa Bay $(0.57 \pm 0.05)$. Anopheles gambiae (s.s.) were collected only in Kisian where they comprised $0.06 \pm 0.01$ of all anophelines, while both An. funestus and An. coustani were collected only in Homa Bay at proportions of $0.04 \pm 0.02$ and $0.38 \pm 0.04$, respectively (Fig. 4a). Collections by HDT-H were predominantly $A n$. arabiensis at both sites $(0.76 \pm 0.1$ of all anophelines in Kisian and $0.82 \pm 0.12$ in Homa Bay). An. gambiae (s.s.) comprised $0.20 \pm 0.1$ of anophelines in Kisian while 0.18 \pm 0.12 of anophelines collected in Homa Bay were $A n$. coustani (Fig. 4b). Comparable proportions of An. arabiensis were collected by HLC in both Kisian and Homa Bay (0.45 \pm 0.05 and $0.46 \pm 0.09$, respectively). The highest proportion of An. gambiae (s.s.), was observed in HLC collections in Kisian, where it made up $0.55 \pm 0.05$ of all anophelines, while An. funestus comprised $0.43 \pm$ 0.09 of all anophelines collected in Homa Bay (Fig. 4c).

Table 1 Numbers of Anopheles and culicine species collected by different treatments for each experiment

\begin{tabular}{|c|c|c|c|c|c|c|c|c|c|c|c|c|c|}
\hline \multirow[t]{2}{*}{ Experiment } & \multirow[t]{2}{*}{ Treatment } & \multicolumn{6}{|c|}{ Anopheles species } & \multicolumn{6}{|c|}{ Culicine species } \\
\hline & & Fed & Gravid & Half gravid & Unfed & Male & $\overline{\text { Total }}$ & Fed & Gravid & Half gravid & Unfed & Male & $\overline{\text { Total }}$ \\
\hline \multirow{3}{*}{$\begin{array}{l}\text { Exp. } 1 \text { (Kisian, } \\
n=24 \text { nights) }\end{array}$} & HDT-C & 1 & 0 & 1 & 1011 & 0 & 1013 & 4 & 1 & 1 & 8610 & 25 & 8641 \\
\hline & HDT-H & 0 & 0 & 1 & 23 & 0 & 24 & 2 & 0 & 1 & 605 & 22 & 630 \\
\hline & $\mathrm{HLC}$ & 21 & 0 & 2 & 120 & 5 & 148 & 47 & 6 & 5 & 1686 & 0 & 1744 \\
\hline \multirow{3}{*}{$\begin{array}{l}\text { Exp. } 1 \text { (Homa } \\
\text { Bay, } n=12 \\
\text { nights) }\end{array}$} & HDT-C & 1 & 0 & 0 & 124 & 0 & 125 & 0 & 0 & 0 & 246 & 0 & 246 \\
\hline & HDT-H & 0 & 0 & 0 & 9 & 0 & 9 & 0 & 0 & 0 & 26 & 0 & 26 \\
\hline & $\mathrm{HLC}$ & 7 & 0 & 1 & 8 & 1 & 16 & 0 & 1 & 6 & 9 & 2 & 18 \\
\hline \multirow{2}{*}{$\begin{array}{l}\text { Exp. } 2 \\
\text { ( } n=6 \\
\text { nights) }\end{array}$} & $\begin{array}{l}\text { Cattle } \\
\text { present }\end{array}$ & 41 & 3 & 6 & 86 & 0 & 136 & 570 & 1 & 33 & 2793 & 1 & 3398 \\
\hline & $\begin{array}{l}\text { Cattle } \\
\text { absent }\end{array}$ & 0 & 0 & 0 & 7 & 0 & 7 & 0 & 0 & 0 & 122 & 1 & 123 \\
\hline \multirow{3}{*}{$\begin{array}{l}\text { Exp. } 3 \\
(n=24 \\
\text { nights })\end{array}$} & O-HDT & 0 & 0 & 0 & 90 & 0 & 90 & 7 & 0 & 0 & 3089 & 31 & 3127 \\
\hline & BG-HDT & 1 & 0 & 0 & 119 & 0 & 120 & 2 & 0 & 0 & 2721 & 9 & 2732 \\
\hline & HLC & 4 & 0 & 0 & 111 & 4 & 119 & 19 & 32 & 30 & 1558 & 9 & 1648 \\
\hline Total & & $76(4.2)$ & $3(0.2)$ & $11(0.6)$ & $1708(94.5)$ & $10(0.6)$ & 1807 & $651(2.9)$ & $41(0.2)$ & $76(0.3)$ & $21,465(96.1)$ & $100(0.4)$ & 22,333 \\
\hline
\end{tabular}




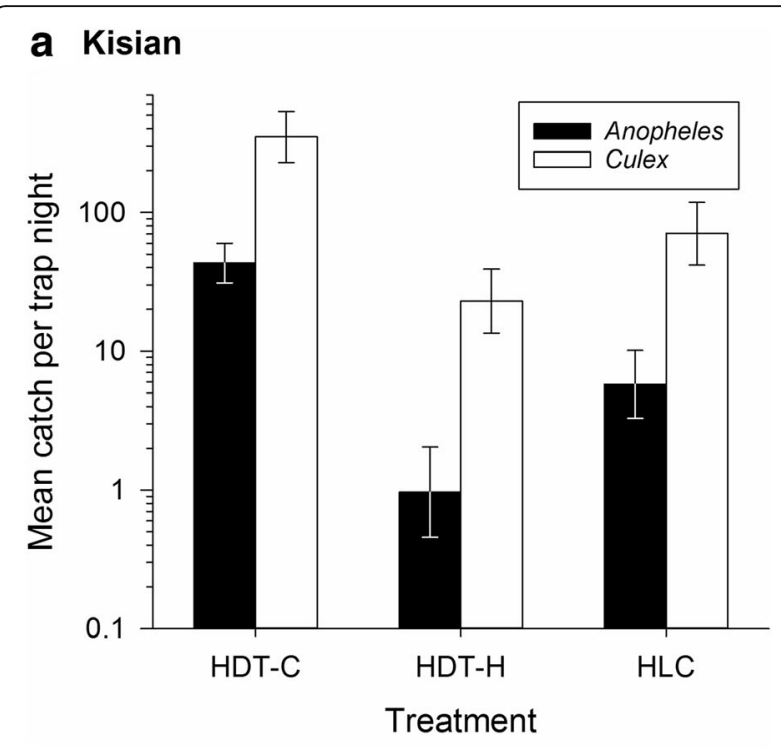

\section{b Homa Bay}

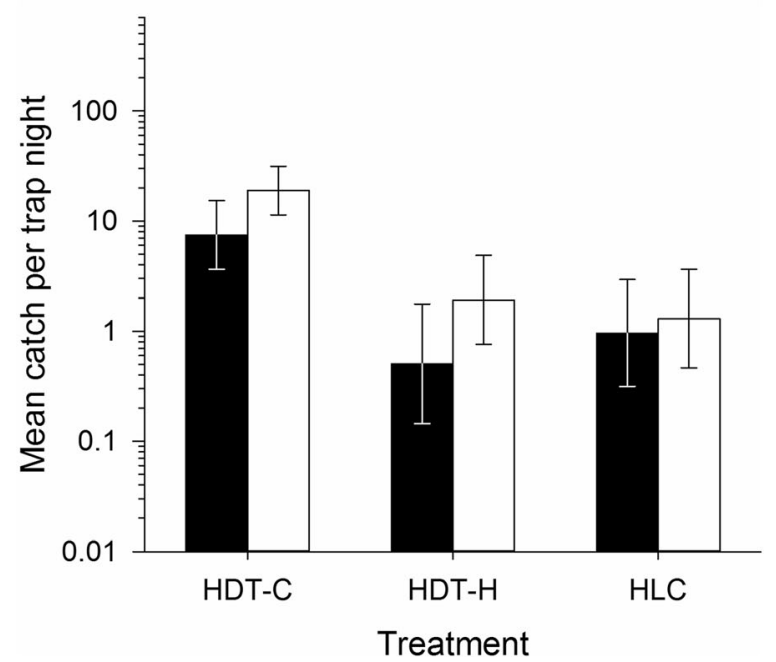

Fig. 3 Nightly outdoor catches (mean \pm standard error) of Anopheles spp. and culicine mosquitoes from cattle-baited HDT (HDT-C), human-baited HDT (HDT-H) and human landing catch (HLC) traps in Kisian ( $n=24$ nights) and Homa Bay ( $n=12$ nights), western Kenya (Experiment 1). Data are plotted on a logarithmic $y$-axis

In Kisian, significantly higher proportions of $A n$. arabiensis were found in HDT-C compared to HDT-H $(z=$ -2.8; $P=0.01)$, and in HDT-H compared to HLC $(z=-2.5$; $P=0.03)$. A significantly lower proportion of An. arabiensis was observed in HLC compared to HDT-C $(z=-12.4$; $P<0.001)$. Significantly higher proportions of $A n$. gambiae (s.s.) were observed in HLC compared to HDT-C ( $z=$ 12.5; $P<0.001)$, HLC compared to HDT-H $(z=2.7 ; P=$ $0.02)$ and HDT-H compared to HDT-C $(z=2.3 ; P=0.05)$. Only two An. funestus were collected by HDT-C in Kisian, hence no analysis was performed on this species.
In Homa Bay, there was no significant difference in the proportion of $A n$. arabiensis caught by the different collection methods. Significantly higher proportions of An. funestus were collected in the HLC compared to HDT-C $(z=4.8 ; P<0.001)$. No An. funestus were collected by HDT-H. An. coustani was sampled by all collection methods. HDT-C collected significantly higher proportions of $A n$. coustani compared to HLC $(z=-2.66$; $P=0.03$ ), while no significant differences were found between HDT-C and HDT-H or between HLC and HDT-H.

\section{Experiment 2: Catches from unbaited HDT}

Unbaited BG-HDTs placed either next to a herd of corralled cattle or in a compound with no cattle present captured Anopheles mosquitoes. The traps collected mostly An. arabiensis at proportions of $0.97 \pm 0.02$ and $0.8 \pm 0.2$ in the presence and absence of cattle, respectively. These differences were not statistically significant. However, the HDT collected a mean of 10.4 (95\% CI: 2.055.0) Anopheles each night in the presence of cattle versus 0.45 (95\% CI: 0.1-1.7) when cattle were absent $(z=-3.81$; $P=0.0001)$. A significantly higher mean number of culicine mosquitoes were collected in the presence of cattle, 314.5 (95\% CI: 70.0-1412.3) versus 3.83 (95\% CI: 1.4$10.5)$ in compounds without cattle $(z=-6.92, P<0.001$; Fig. 5). No sporozoite-positive Anopheles were detected in Experiment 2, however 30\% of Anopheles mosquitoes in the HDT next to cattle were blood-fed, which may reflect partial blood meals on the available cattle (Table 1).

Experiment 3: Trap validation - does the BG-HDT catch similar abundance and species composition as the original trap?

We compared the commercial BG-HDT produced by Biogents and the O-HDT, the original proof of concept version, alongside a standard HLC. We found no significant difference $(z=-0.73 ; P=0.46)$ in the mean nightly outdoor catch of Anopheles between the commercial BG-HDT, which caught 3.33 (95\% CI: 1.4-8.0), and the original version made using locally available materials, which caught 2.66 (95\% CI: 1.1-6.5) per night (Fig. 6). There was also no significant difference in mean nightly Anopheles catch between the commercial BG-HDT and HLC [4.21 (95\% CI: 2.2-7.9); $z=-0.74 ; P=0.46]$. The commercial BG-HDT and O-HDT caught near identical proportions of $A n$. arabiensis (72\% and $69 \%$ of specimens, respectively; $z=-0.50 ; P=0.86)$.

\section{Discussion}

Our results demonstrate that the HDT baited with cattle odour is a highly efficient method of sampling outdoor biting anophelines, with a cattle-baited HDT catching consistently more Anopheles, mainly $A n$. arabiensis, than the HLC. Overall, the cattle-baited HDT caught over 


\section{a HDT-C}

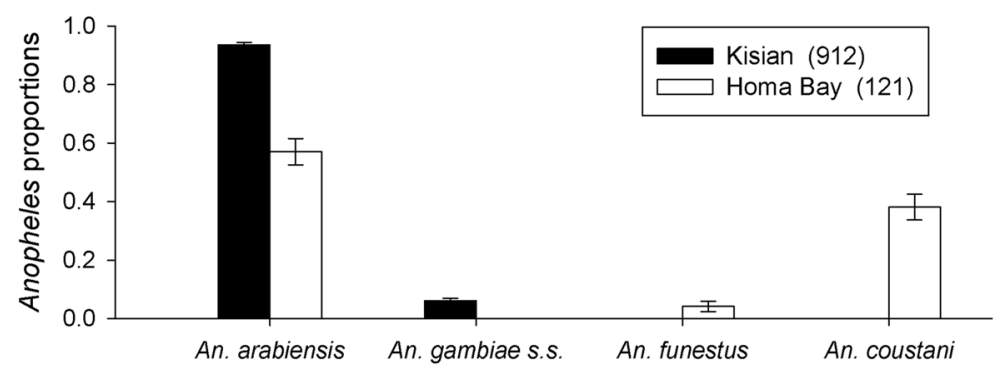

b HDT-H

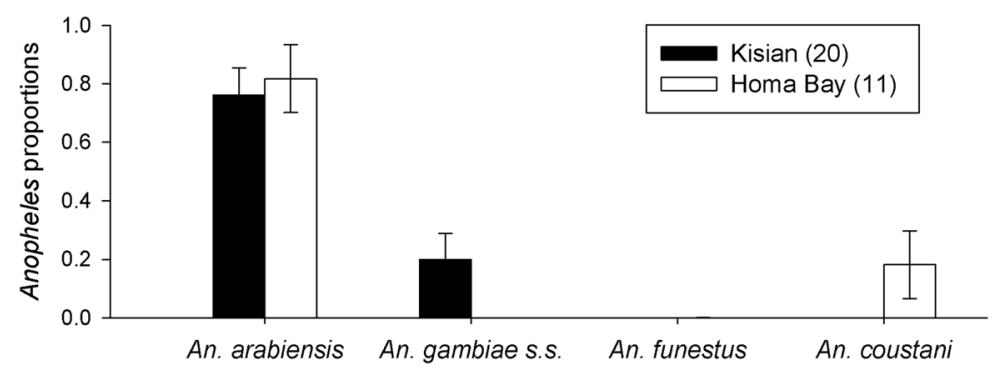

\section{HLC}

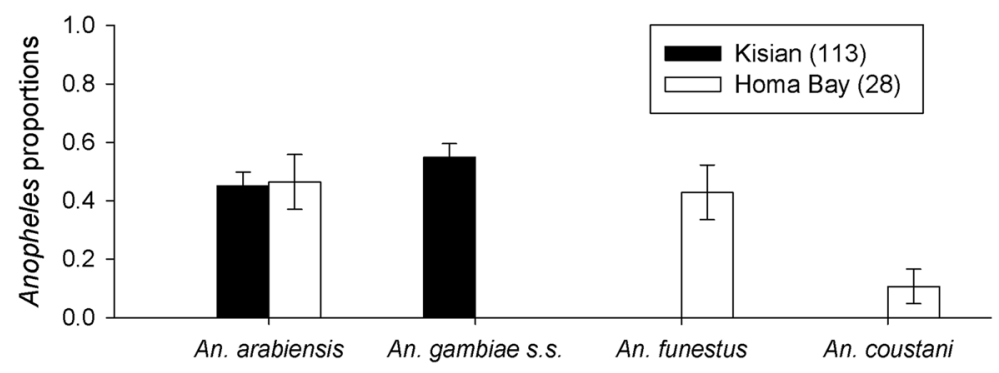

Fig. 4 Relative species composition (proportions \pm standard error) of Anopheles mosquitoes from three outdoor trapping methods [cattle-baited HDT (HDT-C), human-baited HDT (HDT-H) and human landing catch (HLC) traps] in Kisian and Homa Bay, western Kenya (Experiment 1). Numbers in key show total catch of Anopheles caught in Kisian ( $n=24$ nights) and Homa Bay ( $n=12$ nights)

seven times more Anopheles than HLC outdoors. There were also significant differences in the species composition captured by traps baited with different hosts. This result suggests that HDTs may be useful both for collecting large numbers of mosquitoes outdoors, as well as for elucidating mosquito host choice. Our ability to trap mosquitoes when placed in the presence of cattle outdoors demonstrates how the HDT could be deployed as a passive monitoring device for use in outdoor peri-domestic environments. The HDT incorporates sensory stimuli used by host biting mosquitoes to locate their next blood meal and represents a potential new tool for sampling host-seeking mosquitoes, particularly in outdoor environments. The high proportion of unfed Anopheles in HDT collections demonstrate that it is an exposure-free trap. Comparatively, high blood-fed rate in HLC is likely a reflection of potential blood meal from the collectors who are at the risk of potentially infectious mosquito bites. We recommend further improvement of the trap with development of artificial lures that mimic a full arrange of host-associated odours to be used in combination with other mosquito host stimuli for malaria vector surveillance.

The number of Anopheles caught in HDT-H was significantly lower than HLC in the Kisian experiment while no significant difference was observed between the two methods in Homa Bay. In the initial development of the trap, HDT-H caught significantly more Anopheles overall than the HLC [24]. In the present study, local vector populations are composed of $A n$. gambiae (s.s.), An. arabiensis, An. funestus and An. coustani, whereas $A n$. coluzzii is predominant in the area of Burkina Faso where the first evaluation of HDT took place. Given that Experiment 3 confirmed the original prototype used in Burkina Faso [24] showed similar catch abundance and 


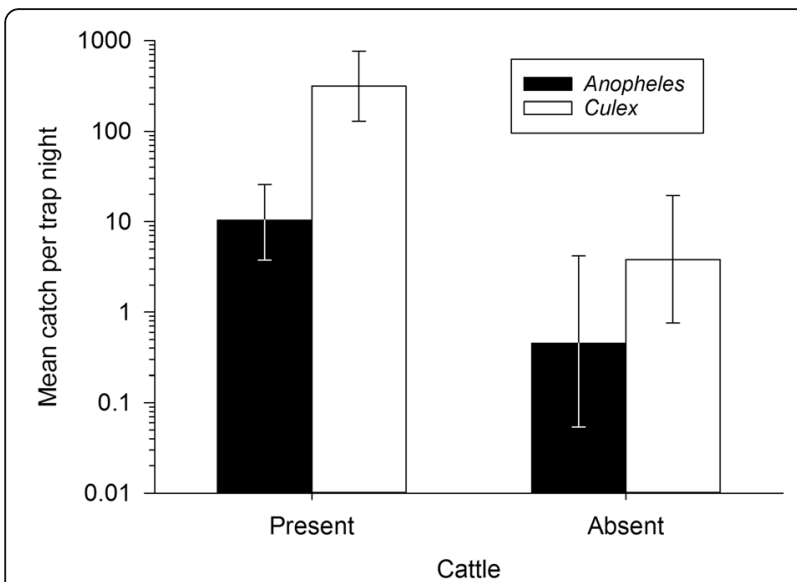

Fig. 5 Comparison of mean ( \pm standard error) catches by Host Decoy Traps in the presence or absence of cattle in Kisian, western Kenya. Mean nightly outdoor catch ( $n=6$ nights/site for each treatment) of Anopheles spp. and culicine mosquitoes (Experiment 2). Data are plotted on a logarithmic y-axis composition to the BG-HDT deployed in Experiments 1 and 2, the observed difference in HDT performance is likely a result of species behavioural differences rather than differences in trapping method. Measurement of $\mathrm{CO}_{2}$ between the HDTs showed that 2.44 times more $\mathrm{CO}_{2}$ was released from the HDT-C tent than the HDT-H tent. However, there were 44 times more Anopheles and $\sim 14$ times more culicines in the HDT-C than in the HDT-H. The effect of differing $\mathrm{CO}_{2}$ concentrations released from the cattle and human tents on the respective $\mathrm{HDT}$ catches demonstrates that there is a non-linear relationship between $\mathrm{CO}_{2}$ and attractiveness to mosquitoes, which merits further research.

Anopheles arabiensis was the predominant species in catches by HDT-C, highlighting the behavior of this species with reference to feeding location and host choice. Previous studies in western Kenya have largely associated $A n$. arabiensis with cattle feeding, and outdoor biting with occasional feeds on humans both indoors and

\section{a Catch}

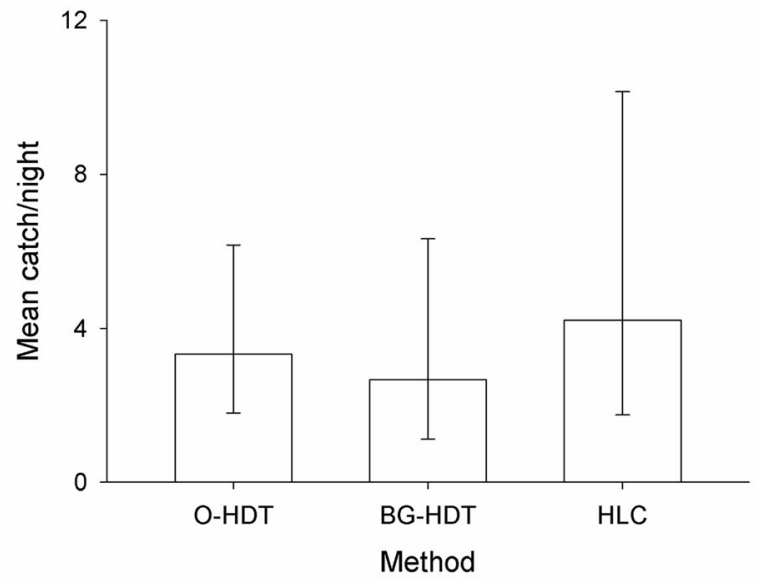

\section{b Composition}

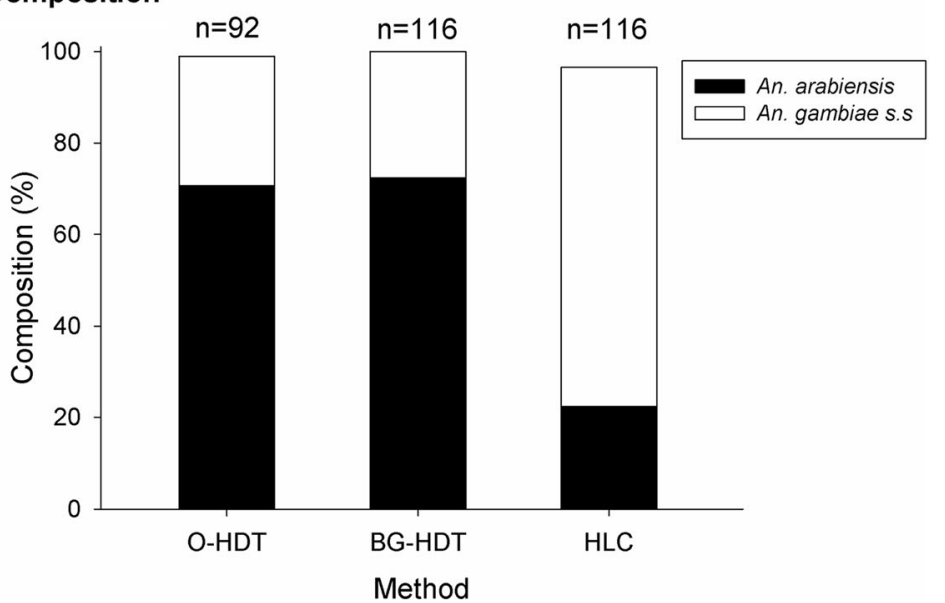

Fig. 6 Nightly outdoor catches (mean $\pm \mathrm{SE} ; n=24$ nights) of Anopheles mosquitoes with the original Host Decoy Trap (O-HDT), the BG-HDT and the human landing catch ( $\mathrm{HLC}$ ), in Kisian, western Kenya (Experiment 3) 
outdoors $[2,26,27,35]$. Even though the overall catch of An. arabiensis was low in both HDT-H and HLC, the vector species comprised a high proportion of Anopheles trapped by the two methods at both sites with some captured mosquitoes having sporozoite infection, indicating previous feeding on humans, although likely at lower rates than An. gambiae or An. funestus. Earlier investigations of $A n$. arabiensis biting behavior in western Kenya found that outdoor resting An. arabiensis did not feed on humans, whereas those caught resting indoors had a human blood index (HBI) of 0.23 [27]. In northern Tanzania, $90.3 \%$ of $A n$. arabiensis were captured in traps baited with cattle odour compared to $9.7 \%$ which were attracted to human odour [36]. In Ethiopia, an evaluation of blood-feeding behavior of An. arabiensis using host-baited sampling methods showed that this species fed preferentially on humans over cattle outdoors, but with a preference for cattle-biting outdoors over human-biting indoors $[25,37]$. These studies illustrate the diversity of feeding behaviour of An. arabiensis, which makes this species particularly difficult to control by LLINs and IRS.

Human-baited traps, HDT-H and HLC caught the largest proportions of An. gambiae (s.s.). While earlier studies investigating host selection reported the species to feed more frequently on humans indoors [2, 26, 27, 35], there is a recent report of an unusually high frequency of animal and mixed blood meals in An. gambiae (s.s.) [10] and a shift in biting time [38] in regions of western Kenya highlands with high bednet coverage. These observations suggest possible behavioral modification in the presence of bednets. While our data are unable to confirm any of these observations, we recommend further studies to determine current contribution of An. gambiae (s.s.) to malaria transmission both indoors and outdoors in the lake endemic regions of western Kenya, following previous reports of historical population decline of the species associated with the introduction of bednets [3].

Additional control tools that target outdoor-biting vector populations are needed to supplement LLINs and IRS [7, 39]. Zooprophylaxis by keeping cattle around houses has been suggested as a strategy to protect humans from malaria [36]. Classical zooprophylaxis (without insecticides) may not have a significant impact on the malaria vectorial capacity of An. arabiensis [37] in regions where the vector bites both humans and cattle. Indeed, the presence of cattle may result in the proliferation of the species and sustain outdoor transmission. However, treating cattle with insecticides or endectocides, such as ivermectin, may be a viable strategy [40]. Recent evaluation of endectocide administration to local Zebu cattle under semi-field conditions in western Kenya showed a significant reduction in survival of An. arabiensis of up to 21 days post-treatment [41]. Furthermore, a field evaluation of topical formulations of eprinomectin against An. arabiensis in western
Kenya showed a $38 \%$ reduction in indoor resting densities of the species within one-week post-treatment [42]. The HDT is suitable for sampling outdoor-biting vectors under such treatments, and therefore, could be a valuable method for monitoring the impact of the next generation of control interventions that target malaria vectors, including periodic assessment of host preference. The numbers of An. arabiensis collected and killed each night by the HDT also raises the question of whether the concept of host decoys can be developed as a behaviour-based vector control tool, similar to the Suna trap [18] or to the lethal targets used to lure and kill tsetse vectors of trypanosomes [43].

\section{Conclusions}

The HDT, which combines odours, heat and a visually-conspicuous stimulus to simulate a host, provides the basis of a system to sample Anopheles mosquitoes, particularly outdoor feeding mosquitoes that tend to feed primarily on other hosts but may be involved in residual transmission of malaria. The cattle-baited HDT is particularly effective for An. arabiensis, an important vector of malaria which feeds, in part, outdoors on cattle and is, therefore, not efficiently sampled or controlled by standard methods. The HDT offers the prospect of a system to monitor and potentially control An. arabiensis and other outdoor-biting mosquitoes more effectively. To achieve a practical, standardized system, the use of artificial host odours to replace the natural odours used in this and previous studies of the HDT should be explored.

\section{Abbreviations}

BG-HDT: Host decoy trap manufactured by Biogents AG; CDC: Centers for disease control and prevention; ELISA: Enzyme-linked immunosorbent assay; GLMM: Generalized linear mixed effects statistical models; HBI: Human blood index; HDT: Host decoy trap; HDT-C: Host decoy trap - cow-baited; HDTH: Host decoy trap - human-baited; HLC: Human landing catch; IRS: Indoor residual spraying; KEMRI/SERU: Kenya Medical Research Institute/ Scientific and Ethics Review Unit; LLIN: Long-lasting insecticidal net; O-HDT: Host decoy trap - original construction; PCR: Polymerase chain reaction; PVC: Polyvinyl chloride

\section{Acknowledgements \\ The authors thank all volunteers who participated in mosquito collection as well as the community of Kisian and Orego villages for their support. We thank also the staff of KEMRI-CGHR for their support, especially Laban Adero for the night supervision of the HLC collectors and Celestine Wekesa, Mathew Kipsum and Brigid Kemei for laboratory analysis of mosquitoes.}

\section{Funding}

This project was supported by the following: Medical Research Council "Human Decoy Trap; operational and social acceptability of novel tool to improve surveillance and control of mosquitoes and other disease vectors", grant number MR/P025404/1. The Eck Institute of Global Health supported trap validation experiments.

\section{Availability of data and materials}

The datasets used during the present study are available from the corresponding author upon reasonable request. 


\section{Disclaimer}

The opinions or assertions contained in this manuscript are the private ones of the authors and are not to be construed as official or reflecting the views of the U.S. Centers for Disease Control and Prevention or the Department of Health and Human Services. Use of trade names is for identification only and does not imply endorsement by U.S. Centers for Disease Control and Prevention or the Department of Health and Human Services.

\section{Authors' contributions}

BA, FMH and SJT conceived the study. BA, FMH, SJT, XY, NFL and MJD participated in design of the experiment. BA, SJT, FMH, XY and MO performed the experiment. BA, SJT, MJD and FMH analyzed the data. FMH, GG and GM developed the BG-HDT. BA, FMH, GG, MJD, SJT, JG, FK, AS, NL, EO and SM wrote and reviewed the manuscript. All authors read and approved the final manuscript.

\section{Ethics approval and consent to participate}

The study was approved by the Kenya Medical Research Institute/ Scientific and Ethics Review Unit (KEMRI/SERU), number 2776 and by CDC through a reliance agreement with KEMRI/SERU (CDC IRB 6728). Individuals participating in HLC gave a written consent. They were screened for malaria and treated if positive. The collectors were placed on malaria prophylaxis, Mephaquin (Acino Pharma AG, Switzerland) one week before collections begun, with repeat doses once every week through the collection period, until four weeks after collections ended. The household head for the compounds used in the study provided consent for use of cows.

\section{Consent for publication}

Not applicable.

\section{Competing interests}

The authors declare they have no competing interests.

\section{Publisher's Note}

Springer Nature remains neutral with regard to jurisdictional claims in published maps and institutional affiliations.

\section{Author details}

'Liverpool School of Tropical Medicine, Pembroke Place, Liverpool L3 5QA, UK. ${ }^{2}$ Centre for Global Health Research, Kenya Medical Research Institute, PO Box 1578-40100, Kisumu, Kenya. ${ }^{3}$ Abt Associates Inc. PMI-VectorLink Kenya, Whitehouse, Milimani, Kisumu, Ojijo Oteko Road, P.O. Box 895-40123, Kisumu, Kenya. ${ }^{4}$ Eck Institute for Global Health, Department of Biological Sciences, University of Notre Dame, Notre Dame, IN 46556, USA. " Biogents AB GmbH, Regensburg, Germany. ${ }^{6}$ Natural Resources Institute, University of Greenwich at Medway, Chatham Maritime, Kent ME4 4TB, UK. ${ }^{7}$ Division of Parasitic Diseases and Malaria, Center for Global Health, Centers for Disease Control and Prevention, Atlanta, GA 30333, USA. ${ }^{8}$ Centers for Disease Control and Prevention, Kisian Campus, Off Busia Road, P O Box 1578, Kisumu 40100, Kenya.

\section{Received: 8 May 2018 Accepted: 5 September 2018}

\section{Published online: 15 October 2018}

\section{References}

1. Bhatt S, Weiss DJ, Cameron E, Bisanzio D, Mappin B, Dalrymple U, et al. The effect of malaria control on Plasmodium falciparum in Africa between 2000 and 2015. Nature. 2015;526:207-11.

2. Bayoh MN, Mathias DK, Odiere MR, Mutuku FM, Kamau L, Gimnig JE, et al. Anopheles gambiae: historical population decline associated with regional distribution of insecticide-treated bed nets in western Nyanza Province, Kenya. Malar J. 2010;9:62

3. Gimnig JE, Vulule JM, Lo TQ, Kamau L, Kolczak MS, Phillips-Howard PA, et al. Impact of permethrin-treated bed nets on entomologic indices in an area of intense year-round malaria transmission. Am J Trop Med Hyg. 2003;68:16-22.

4. Lindblade KA, Gimnig JE, Kamau L, Hawley WA, Odhiambo F, Olang G, et al. Impact of sustained use of insecticide-treated bednets on malaria vector species distribution and culicine mosquitoes. J Med Entomol. 2006;43:428-32.

5. Killeen GF, Govella NJ, Lwetoijera DW, Okumu FO. Most outdoor malaria transmission by behaviourally-resistant Anopheles arabiensis is mediated by mosquitoes that have previously been inside houses. Malar J. 2016;15:225.
6. Reddy MR, Overgaard HJ, Abaga S, Reddy VP, Caccone A, Kiszewski AE, et al. Outdoor host seeking behaviour of Anopheles gambiae mosquitoes following initiation of malaria vector control on Bioko Island, Equatorial Guinea. Malar J. 2011:10:184.

7. Russell TL, Govella NJ, Azizi S, Drakeley CJ, Kachur SP, Killeen GF. Increased proportions of outdoor feeding among residual malaria vector populations following increased use of insecticide-treated nets in rural Tanzania. Malar J. 2011;10:80.

8. Mathenge EM, Gimnig JE, Kolczak M, Ombok M, Irungu LW, Hawley WA. Effect of permethrin-impregnated nets on exiting behavior, blood feeding success, and time of feeding of malaria mosquitoes (Diptera: Culicidae) in western Kenya. J Med Entomol. 2001;38:531-6.

9. Sougoufara S, Diedhiou SM, Doucoure S, Diagne N, Sembene PM, Harry M, et al. Biting by Anopheles funestus in broad daylight after use of long-lasting insecticidal nets: a new challenge to malaria elimination. Malar J. 2014;13:125.

10. Ndenga BA, Mulaya NL, Musaki SK, Shiroko JN, Dongus S, Fillinger U. Malaria vectors and their blood-meal sources in an area of high bed net ownership in the western Kenya highlands. Malar J. 2016;15:76.

11. Wong J, Bayoh N, Olang G, Killeen GF, Hamel MJ, Vulule JM, et al. Standardizing operational vector sampling techniques for measuring malaria transmission intensity: evaluation of six mosquito collection methods in western Kenya. Malar J. 2013;12:143.

12. Matowo NS, Moore J, Mapua S, Madumla EP, Moshi IR, Kaindoa EW, et al. Using a new odour-baited device to explore options for luring and killing outdoor-biting malaria vectors: a report on design and field evaluation of the Mosquito Landing Box. Parasit Vectors. 2013;6:137.

13. Torr SJ, Della Torre A, Calzetta M, Costantini C, Vale GA. Towards a fuller understanding of mosquito behaviour: use of electrocuting grids to compare the odour-orientated responses of Anopheles arabiensis and An. quadriannulatus in the field. Med Vet Entomol. 2008;22:93-108.

14. Zwiebel $L$, Takken W. Olfactory regulation of mosquito-host interactions. Insect Biochem Mol Biol. 2004;34:645-52.

15. Mukabana WR, Mweresa CK, Otieno B, Omusula P, Smallegange RC, van Loon JJ, et al. A novel synthetic odorant blend for trapping of malaria and other African mosquito species. J Chem Ecol. 2012;38:235-44.

16. Xue RD, Doyle MA, Kline DL. Field evaluation of CDC and Mosquito Magnet $X$ traps baited with dry ice, $\mathrm{CO}_{2}$ sachet, and octenol against mosquitoes. J Am Mosq Control Assoc. 2008;24:249-52.

17. Hiscox A, Otieno B, Kibet A, Mweresa CK, Omusula P, Geier M, et al. Development and optimization of the Suna trap as a tool for mosquito monitoring and control. Malar J. 2014;13:257.

18. Homan T, Hiscox A, Mweresa CK, Masiga D, Mukabana WR, Oria P, et al. The effect of mass mosquito trapping on malaria transmission and disease burden (SolarMal): a stepped-wedge cluster-randomised trial. Lancet. 2016;388:1193-201.

19. Cooperband MF, Cardé RT. Orientation of Culex mosquitoes to carbon dioxide-baited traps: flight manoeuvres and trapping efficiency. Med Vet Entomol. 2006;20:11-26.

20. Gibson G, Torr SJ. Visual and olfactory responses of haematophagous Diptera to host stimuli. Med Vet Entomol. 1999;13:2-23.

21. Hawkes F, Gibson G. Seeing is believing: the nocturnal malarial mosquito Anopheles coluzzii responds to visual host-cues when odour indicates a host is nearby. Parasit Vectors. 2016;9:320.

22. Achee N, Youngblood L, Bangs M, Lavery JV, James SO. Considerations for the use of human participants in vector biology research: a tool for investigators and regulators. Vector Borne Zoonotic Dis. 2015;15:89-102.

23. Spitzen J, Spoor CW, Grieco F, ter Braak C, Beeuwkes J, van Brugge SP, et al. A 3D analysis of flight behavior of Anopheles gambiae sensu stricto malaria mosquitoes in response to human odor and heat. PloS One. 2013;8:e62995.

24. Hawkes FM, Dabire RK, Sawadogo SP, Torr SJ, Gibson G. Exploiting Anopheles responses to thermal, odour and visual stimuli to improve surveillance and control of malaria. Sci Rep. 2017;7:17283.

25. Tirados I, Gibson G, Young S, Torr SJ. Are herders protected by their herds? An experimental analysis of zooprophylaxis against the malaria vector Anopheles arabiensis. Malar J. 2011;10:68.

26. Githeko AK, Adungo NI, Karanja DM, Hawley WA, Vulule JM, Seroney IK, et al. Some observations on the biting behavior of Anopheles gambiae s.S., Anopheles arabiensis, and Anopheles funestus and their implications for malaria control. Exp Parasitol. 1996;82:306-15.

27. Githeko AK, Service MW, Mbogo CM, Atieli FK, Juma FO. Origin of blood meals in indoor and outdoor resting malaria vectors in western Kenya. Acta Trop. 1994;58:307-16. 
28. KMIS. Kenya Malaria Indicator Survey Nairobi. Kenya: National Malaria Control Programe, Kenya Ministry of Health; 2015.

29. Gillies MT, Coetzee M. A supplement to the Anophelinae of Africa South of the Sahara (Afrotropical region). Johannesburg: South African Institute for Medical Research; 1987.

30. Gillies MT, DeMeillon B. The Anophelinae of Africa South of the Sahara (Ethiopian zoogeographical region). Johannesburg: South African Institute for Medical Research; 1968.

31. Scott JA, Brogdon WG, Collins FH. Identification of single specimens of the Anopheles gambiae complex by the polymerase chain reaction. Am J Trop Med Hyg. 1993:49:520-9.

32. Cohuet A, Simard F, Toto J, Kengne P, Coetzee M, Fontenille D. Species identification within the Anopheles funestus group of malaria vecors in Cameroon and evidence for a new species. Am J Trop Med Hyg. 2003;69: 200-5.

33. Wirtz RA, Zavala F, Charoenvit Y, Campbell GH, Burkot TR, Schneider I, et al. Comparative testing of monoclonal antibodies against Plasmodium falciparum sporozoites for ELISA development. Bull World Health Organ. 1978;65:39-45.

34. Fournier DA, Skaug HJ, Ancheta J, lanelli J, Magnusson A, Maunder MN, et al. AD Model \{B\}uilder: using automatic differentiation for statistical inference on highly parameterized complex nonlinear models. Optim Methods Softw. 2012;27:233-49.

35. Mathias DK, Ochomo E, Atieli F, Ombok M, Bayoh MN, Olang G, et al. Spatial and temporal variation in the Kdr allele L1014S in Anopheles gambiae s.s. and phenotypic variability in susceptibility to insecticides in western Kenya. Malar J. 2011;10:10

36. Mahande A, Mosha F, Mahande J, Kweka E. Feeding and resting behaviour of malaria vector, Anopheles arabiensis with reference to zooprophylaxis. Malar J. 2007;6:100

37. Tirados I, Costantini C, Gibson G, Torr SJ. Blood-feeding behaviour of the malarial mosquito Anopheles arabiensis: implications for vector control. Med Vet Entomol. 2006;20:425-37.

38. Ototo EN, Mbugi JP, Wanjala CL, Zhou G, Githeko AK, Yan G. Surveillance of malaria vector population density and biting behaviour in western Kenya. Malar J. 2015;14:244.

39. Zhu L, Muller GC, Marshall JM, Arheart KL, Qualls WA, Hlaing WM, et al. Is outdoor vector control needed for malaria elimination? An individual-based modelling study. Malar J. 2017;16:266.

40. Yakob L. Endectocide-treated cattle for malaria control: a coupled entomological-epidemiological model. Parasit Epidemiol Control. 2016;1:2-9.

41. Poche RM, Burruss D, Polyakova L, Poche DM, Garlapati RB. Treatment of livestock with systemic insecticides for control of Anopheles arabiensis in western Kenya. Malar J. 2015;14:351.

42. Lozano-Fuentes S, Kading RC, Hartman DA, Okoth E, Githaka N, Nene V, et al. Evaluation of a topical formulation of eprinomectin against Anopheles arabiensis when administered to Zebu cattle (Bos indicus) under field conditions. Malar J. 2016;15:324

43. Torr SJ, Vale GA. Know your foe: lessons from the analysis of tsetse fly behaviour. Trends Parasitol. 2015:31:95-9.

Ready to submit your research? Choose BMC and benefit from:

- fast, convenient online submission

- thorough peer review by experienced researchers in your field

- rapid publication on acceptance

- support for research data, including large and complex data types

- gold Open Access which fosters wider collaboration and increased citations

- maximum visibility for your research: over $100 \mathrm{M}$ website views per year

At BMC, research is always in progress.

Learn more biomedcentral.com/submissions 